\title{
Longitudinal Examination of the Relationship Between Supplies-Values Fit and Work Outcomes
}

\author{
Ruben Taris* and Jan A. Feij \\ Vrije Universiteit Amsterdam, The Netherlands
}

Cette étude est centrée sur la force de la relation entre la correspondance contributions-valeurs (supplies-values ou $\mathrm{S}-\mathrm{V}$ ) et les résultats du travail. Plus particulièrement, la forme fonctionnelle qui décrit le mieux les rapports des trois dimensions de la correspondance $\mathrm{S}-\mathrm{V}$ (c'est-à-dire les relations sociales $\mathrm{au}$ travail et les aspects intrinsèques et extrinsèques du travail) avec la satisfaction professionnelle, le projet de quitter l'organisation et le bien-être psychologique a été explorée à l'aide de la technique de la régression modérée proposée par Edwards (1991, 1994). Cette recherche élargit les travaux antérieurs en s'intéressant à la stabilité de ces relations à deux périodes séparées par un laps de temps de quatre ans. Les analyses montrent que la forme fonctionnelle de la relation de la correspondance $\mathrm{S}-\mathrm{V}$ avec les résultats du travail différent selon les dimensions de la correspondance $\mathrm{S}-\mathrm{V}$ et selon les aspects des résultats du travail pris en considération. Cependant, la forme fonctionnelle de chacune de ces relations sur la première période était presque identique à la forme des relations sur la seconde. En outre, les analyses montrent que les trois dimensions de la correspondance $\mathrm{S}-\mathrm{V}$ affectent la satisfaction professionnelle et le projet de démission, mais n'ont qu'un faible effet sur le bien-être psychologique. La composante "contribution organisationnelle", aussi bien que son terme quadratique en particulier, a une grande influence sur la satisfaction professionnelle et le projet de départ. On discute aussi des retombées sur les futures recherches dans le domaine personneorganisation.

This study focuses on the robustness of the relationship between suppliesvalues (S-V) fit and work outcomes. Specifically, the functional form that best describes the relationships of three different dimensions of $\mathrm{S}-\mathrm{V}$ fit (i.e. intrinsic work aspects, extrinsic work aspects, and social relations at work) with job satisfaction, intention to leave the organisation and psychological well-being was investigated using the moderated regression technique proposed by Edwards (1991, 1994). This study extends previous research by examining the

\footnotetext{
* Address for correspondence: Ruben Taris, Haarlemmerweg 269-C, 1051 NW Amsterdam, The Netherlands. Email: rta@LTP.nl or JA.Feij@psy.vu.nl 
stability of these relationships across two occasions, separated by a period of four years. Results showed that the functional form of the relationship of S-V fit with work outcomes differed by the $\mathrm{S}-\mathrm{V}$ fit dimension and the work outcome under investigation. However, the functional form of each of these relationships on the first occasion was almost identical to the form of the relationships on the second occasion. Additionally, results showed that all three $\mathrm{S}-\mathrm{V}$ fit dimensions affected job satisfaction and intention to leave, but had only a weak effect on psychological well-being. The organisational supplies component, as well as its quadratic term in particular, had a large influence on job satisfaction and intention to leave. Implications for future research in the $\mathrm{P}-\mathrm{O}$ fit area are discussed.

\section{INTRODUCTION}

The notion that behaviour is determined by the interaction between personal characteristics and environmental properties (Lewin, 1951) is nowadays generally accepted by work and vocational psychologists. For example, Dawis and Lofquist (1984) applied this idea in their theory of work adjustment and Holland (1992) in his congruence theory. A central assumption in these theories is that the congruence or fit between a person and his or her work environment ( $\mathrm{P}-\mathrm{E}$ fit) is an important predictor of work outcomes, most notably job satisfaction, commitment, tenure, employee well-being, and vocational choice. Although there is a wealth of evidence from empirical research that supports this relationship (for reviews, see Assouline \& Meir, 1987; Edwards, 1991; Kristof, 1996; Spokane, 1985), the exact shape of the relationship between $\mathrm{P}-\mathrm{E}$ fit and work outcomes is not always specified.

There are several functional forms that could delineate the relationship between a person, the environment, and work outcomes. It is generally assumed that a good or optimal fit leads to positive work outcomes, while poor fit is usually associated with negative results. In some cases, the relationship between P-E fit and work outcomes may be assumed to be U-shaped or inverted U-shaped. For example, an employee will only be satisfied when the amount of supervision supplied by his or her executive matches the amount of supervision desired by this employee; excess support as well as lack of support from the supervisor will lead to job dissatisfaction.

These kinds of U-shaped relations are expected for certain environmental features, such as task variety and autonomy. However, when other environmental features are considered, such as availability of money, physical security, and valued social position, work outcomes are unlikely to be affected by having too much (Locke, 1976; Mahoney, 1979; Warr, 1987). Only lack of these environmental features would affect work outcomes. So, when a person has less knowledge about computers than required by the job, this

(C) International Association for Applied Psychology, 2001. 
person would be unable to perform effectively in that job, but it is unlikely that performance will be affected when his or her knowledge about computers exceeds the demands of the job. However, this may be true only when performance as a work outcome is considered, but not when this type of fit is examined related to job satisfaction. Job dissatisfaction probably occurs when knowledge about computers is left idle. In summary, the form of the relationship between $\mathrm{P}-\mathrm{E}$ fit and work outcomes seems to depend on the person, the nature of the environment, and the type of outcome variables concerned.

While in most P-E fit studies it is assumed that an interaction between a person and the environment is strongly related to work outcomes, the main effects of the person and his or her environment may already explain a large amount of variance. Studies investigating the influence of personal and environmental characteristics on work outcomes have found that environmental properties accounted for most of the variance in these work outcomes (Cohen, 1992; Hesketh \& Gardner, 1993; Livingstone, Nelson, \& Barr, 1997; Mathieu \& Zajac, 1990; Meyer, Irving, \& Allen, 1998; O’Brien \& Dowling, 1980; Rice, Markus, Moyer, \& McFarlin, 1991). Nevertheless, the effects of the interaction of people with their work environment still added significant incremental variance to work outcomes in most of these studies.

\section{Fit Between Work Values and Organisational Supplies}

In P-E fit literature, various types of P-E fit are identified. Kristof (1996), for instance, distinguishes four types of $\mathrm{P}-\mathrm{E}$ fit based on different environmental levels: person-organisation fit, person-vocation fit, person-group fit, and person-job fit. Although the last three types of fit may also have a substantial contribution in predicting work outcomes, the focus of the present study is on person-organisation $(\mathrm{P}-\mathrm{O})$ fit.

An important category of person variables studied in $\mathrm{P}-\mathrm{O}$ fit research is work values (Edwards, 1996; Hesketh \& Gardner, 1993; Livingstone et al., 1997; Locke, 1976; Meyer et al., 1998; MOW, 1987). Values are defined as enduring beliefs that a specific mode of conduct or end-state is preferable to its opposite, thereby guiding individuals' attitudes, judgments, and behaviours (Chatman, 1989, 1991; Rokeach, 1973). According to Locke (1976), work values shape the way in which individuals view supplies offered by the organisation. He proposes that the relationship between organisational supplies and job satisfaction varies as a function of work values. Therefore, Locke made a clear distinction between values and needs. In his view, needs are elements that ensure an individual's survival, much in the sense that we use the term biological need. Needs are objective, existing regardless of the desires of a person. In contrast, values are subjective, or to put it more simply, are something a person desires at either a conscious or subconscious level. Given this distinction, Locke (1976) defines job satisfaction as "the

(C) International Association for Applied Psychology, 2001. 
pleasurable emotional state resulting from the perception of one's job as fulfilling or allowing the fulfillment of one's important job values, providing these values are compatible with one's needs" (p. 1342).

Thus, Locke suggests that the importance of a particular job aspect defines the range of job satisfaction, rather than the actual satisfaction with that job aspect. In other words, if something is relatively unimportant to a person, he or she will be relatively indifferent regardless of the amount of that job element received. On the other hand, if the person values a particular job aspect very highly, then slight variations from optimal amounts of that job aspect will produce wide variations in job satisfaction. Moreover, the overall amount of job satisfaction is not the simple sum of satisfactions with individual elements of the job. The importance of a particular job aspect determines the contribution of the amount of satisfaction with that job aspect to one's overall amount of job satisfaction. Thus, if task variety is extremely important and salary is relatively unimportant to a person, task variety should play a greater role in determining that person's overall job satisfaction than salary.

With regard to work values $(\mathrm{V})$, a commonly used differentiation in this domain is in intrinsic, extrinsic, and social work values (Ginzberg, Ginsburg, Axelrad, \& Herma, 1951; MOW International Research Team, 1987; WOSY International Research Group, 1989). Intrinsic work values refer to the degree to which employees value immaterial aspects of their jobs that allow for self-expression as important, for example, job variety and autonomy. Extrinsic work values refer to the degree to which employees value material or instrumental work aspects, such as salary and opportunity for promotion, as important. Social work values refer to the degree to which employees find it important having a good relationship with their coworkers and supervisor. Organisational supplies (S) are a particular class of work experiences referring to aspects of the work environment that satisfy the three aforementioned work values to a greater or lesser extent. In the present study, organisational supplies and work values are measured on commensurate dimensions; these dimensions are intrinsic work aspects, extrinsic work aspects, and social relations at work.

Some authors (Locke, 1976; Mahoney, 1979; Warr, 1987) suggest that increments of all kinds of job elements (in our study: intrinsic work aspects, extrinsic work aspects, and social relations at work) are beneficial to an employee's job satisfaction and psychological well-being until a certain level is attained. This level or satiation point can be conceptualised as the point where supplies offered by the organisation equal the values of the employee. Beyond this satiation point, the effect for each of these environmental work aspects on work outcomes seems to differ. For instance, Warr's (1987) "vitamin model" hypothesises that for intrinsic work aspects, such as work autonomy or variety, and social relations at work extreme levels beyond this

(C) International Association for Applied Psychology, 2001. 
satiation point will lead to a reduction in mental health as well as a reduction in job satisfaction. In other words, an inverted U-relationship is expected between intrinsically rewarding work characteristics and job satisfaction or "context-free" well-being. On the other hand, Warr proposes that for extrinsic work aspects, such as availability of money, physical security, and valued social position, any addition beyond the satiation point will have no further effect: the initially rising curve will reach an asymptotic level when more money or physical security is supplied by the organisation. Other authors (Locke, 1976; Mahoney, 1979) also assume that the functional relationship between perceived levels of work elements and overall job satisfaction may take different forms, dependent on the work element concerned and the employee's valued level of that work characteristic. Mahoney (1979), for instance, suggests that any increase in intrinsically rewarding work aspects, such as interesting work, skill development, and opportunities for personal growth, beyond a certain valued level will lead to further enhancement of job satisfaction. For other (extrinsically rewarding) job aspects, such as physical working conditions, salary, or promotion opportunities, curvilinear relationships between perceived levels and satisfaction are suggested by Mahoney's (1979) satiation model. In these cases, satisfaction reaches an optimum at the point where the perceived level of the environment is equal to the employee's valued level, and then remains at a constant level, or decreases. However, the aforementioned effects of intrinsic work aspects, extrinsic work aspects and social relations at work on work outcomes rely almost exclusively on conceptual reasoning, rather than on empirical evidence.

This study extends the previous research on the relationship between supplies-values (S-V) fit and work outcomes by examining two issues that have not been extensively addressed. First, our study examines the form of the relationships of three different dimensions of S-V fit (i.e. intrinsic work aspects, extrinsic work aspects, and social relations at work) with job satisfaction, intention to leave, and psychological well-being. As will be explained later, both linear and curvilinear main effects of work values and organisational supplies on the dependent variables, as well as $S^{*} V$ interactions are taken into consideration. A second contribution of this study is that data were gathered in a longitudinal design allowing examination of the robustness of these relationships over a time period of four years.

\section{Purpose and Hypotheses}

The main aim of this study is to explore the functional form of the relationships of three different dimensions of $\mathrm{S}-\mathrm{V}$ fit (i.e. intrinsic and extrinsic work aspects, and social relations at work) with work outcomes, such as job satisfaction, intention to leave, and psychological well-being,

(C) International Association for Applied Psychology, 2001. 
using moderated regression analysis as proposed by Edwards $(1991,1994)$. This analysis yields separate estimates of the relationships of the main components $(S$ and $V)$, their quadratic terms $\left(S^{2}\right.$ and $\left.V^{2}\right)$, and their interaction $\left(S^{*} V\right)$ with work outcomes. Consequently, effects of work values and organisational supplies on work outcomes are not confounded. Moreover, linear as well as nonlinear relationships between the work values, the organisational supplies and work outcomes can be identified. Further, interpretation of the results can be readily facilitated by visual inspection of three-dimensional plots of estimated surfaces relating supplies, values, and work outcomes.

The first question to be answered regards the relative contribution of work values and organisational supplies to an employee's job satisfaction, intention to leave, and psychological well-being. We expect that perceived characteristics of the organisation or work environment have a direct effect on work outcomes. Employees who are disappointed about their autonomy, salary, promotion opportunities, social relations at work, or whatever organisational supply, will not feel at ease and will develop withdrawal behaviour. In contrast, direct effects of employees' work values on work outcomes will be smaller or even absent, since the question whether or not a particular value has an effect seems to depend on the work environment or the employee's type of work. For example, an employee who has no strong need for autonomy will hardly experience negative effects if he or she has a job in which autonomy is absent. However, this employee will experience dissatisfaction if the job requires a lot of autonomy. Likewise, a person with a strong need for autonomy will experience difficulties in jobs where autonomy is not desired. In other words, the role of work values will primarily show up as a moderator of the effects of organisational supplies on work outcomes. This is one of the assumptions in Warr's (1987) vitamin model. Although work values as such may have some effects on work outcomes, such as job satisfaction or intention to leave, there is strong empirical evidence that these outcomes are primarily influenced by characteristics of the work or organisational environment (Cohen, 1992; Hesketh \& Gardner, 1993; Livingstone et al., 1997; Mathieu \& Zajac, 1990; Meyer et al., 1998; O’Brien \& Dowling, 1980; Rice et al., 1991). In line with previous research, we hypothesise that work outcomes are predominantly determined by organisational supplies and to a lesser degree or not at all by work values as such (Hypothesis 1). Hence, there will be main effects of organisational supplies on job satisfaction and psychological well-being (positive effects), and on intention to leave (negative effects), while such main effects will be weaker or absent for work values.

In line with the foregoing arguments, we further hypothesise stronger relationships between organisational supplies and work outcomes for persons who consider the organisational supply in question as important than for those who do not (Hypothesis 2). Thus, there will be moderating

(C) International Association for Applied Psychology, 2001. 
effects of work values, that will take the form of significant supplies $\times$ values $\left(S^{*} V\right)$ interactions.

Finally, the exact form of the relationship between S-V fit and a work outcome is expected to depend on the specific work aspect and work outcome concerned. We expect that the effects of increments of the three different work aspects (i.e. intrinsic work aspects, extrinsic work aspects, and social relations at work) on work outcomes will not differ until a certain level of satiation is attained. For all three work aspects, we expect that increments of these work aspects will lead to a higher level of job satisfaction and psychological wellbeing and less intention to leave until this satiation point is reached. At this satiation point organisational supplies equals the employee's valued level. Beyond this point of satiation we hypothesise different effects for the three work values/supplies domains. As predicted by Warr's (1987) vitamin model, further increments of intrinsic work aspects and social relations at work beyond the satiation point are expected to lead to a reduction in job satisfaction and a reduction in psychological well-being, as well as an increase in intention to leave. In other words, job satisfaction and psychological well-being will be low and intention to leave will be high, not only when the employee's valued level exceeds the amount of organisational supplies but also when organisational supplies exceed the employee's valued level (Hypothesis 3). For extrinsic work aspects, however, job satisfaction and psychological well-being will be low and intention to leave will be high only when the employee's valued level exceeds the organisational supplies (Hypothesis 4).

Because this study is part of a longitudinal research project, we can compare the findings concerning the relationship between work values, organisational supplies, and work outcomes on two different occasions (see Method section). Thus, we are able to ascertain the robustness of our findings by comparing the results on one occasion with the results on a second occasion four years later. Additionally, it should be noted that data were gathered from people in a wide range of jobs, companies, and industries, thus avoiding problems associated with a restriction of range in the measurement of the person and the organisation components (Edwards, 1991; Livingstone et al., 1997).

In summary, the aim of this study is to separate the effects of different kinds of work values and organisational supplies and their interactions on work outcomes, and to determine the robustness of these effects.

\section{METHOD}

\section{Sample and Measures}

The present study is part of a large research project in the Netherlands, called "The process of social integration of young adults" (The SI-project;

(C) International Association for Applied Psychology, 2001. 
Dijkstra, 1989, 1993). The purpose of the SI-project was to study the process of social integration over time as well as personal and social components that improve or hinder this process. Interview and questionnaire data were collected in a longitudinal design on two successive occasions with an interval of four years. Participants were Dutch young adults, male and female, who were 18, 22, and 26 years old at the first occasion; $46 \%$ of them were women. The sampling procedure consisted of two steps. First, 20 municipalities in the Netherlands, stratified to four regions and five levels of urbanisation, were drawn. Next, 2,800 home addresses of persons in the aforementioned age groups were randomly selected from the registry offices in these municipalities. These persons received a letter in which their participation was requested.

At the first occasion (T1), 1,775 young adults completed a self-report questionnaire and were interviewed by trained interviewers, using a structured interview schedule. The sample was almost representative of the Dutch population in the age groups mentioned above; the sample consisted of a wide range of occupations and job levels. At the second occasion (T2), 1,257 participants cooperated again. Compared to the first occasion, the educational level of these young adults was somewhat higher, implying that more well-educated participants were involved. With respect to sex, age, and socioeconomic status, no sample attrition effects were found (for more details about the attrition effects of the SI-panel see Taris, Van der Vaart, \& Dijkstra, 1993).

For the present study, only those participants of the SI-panel were selected who were employed for more than 19 hours a week (i.e. at least a half-time job) at either of the two occasions. Through listwise deletion of missing values, the final sample consisted of 467 subjects. In the present study, no distinction was made between participants in the same job and participants who changed jobs, because statistical power would be limited due to the sample size of these two subsamples (there were only 212 participants that held the same job on both occasions).

\section{Independent Variables}

Work Values. At both occasions, work values were measured by means of a self-report questionnaire. This questionnaire comprised three scales, ${ }^{1}$ based on the categorisation of Ginzberg et al. (1951), the MOW project (1987), and the WOSY International Research Group (1989). These scales refer to extrinsic work aspects (six items), intrinsic work aspects (six items), and social relations at work (three items). The six items of the extrinsic work

${ }^{1}$ The items are available from the authors.

(C) International Association for Applied Psychology, 2001. 
aspects scale measure instrumental aspects of work. Sample items included "salary", "opportunity for promotion", and "job security". The scale depicting intrinsic work aspects refers to aspects of work, such as "autonomy", "task variety", and "responsibility". The three items measuring social relations at work focus on the importance one attaches to social aspects of work, specifically relationships with coworkers and supervisor, and pleasantness of the working atmosphere in general. Participants were asked to indicate on a five-point Likert-type scale, ranging from (1) very unimportant to (5) very important, how important it is to them to have a job with each of the listed work aspects. Internal consistencies of the scales are presented in Table 1.

Organisational Supplies. These were measured at the two occasions by means of a series of structured interview questions. In this case structured interview questions were used instead of a self-report questionnaire. The number and formulation of the interview items as well as the three scales that were formed by these items corresponded exactly to those of the work values questionnaire, in order to fulfil the requirement of commensurate measurement of person and environmental characteristics (Dawis \& Lofquist, 1984; French, Caplan, \& Van Harrison, 1982). The participants rated their present job. They were asked: "To what extent is each of the following aspects present in your actual job?" The interviewer then mentioned the same work aspects as were listed in the Work Values Questionnaire (see above). Following the interviewer's mention of each work aspect, participants indicated its presence in their actual job on a five-point Likert-type scale. The response alternatives ranged from (1) very little to (5) very much and were presented to participants on a card. Internal consistencies of the organisational supplies scales are presented in Table 1.

\section{Dependent Variables}

Job Satisfaction. This was measured by one item ("How satisfied are you, all in all, with your current job?") and rated on a five-point scale (range: $1=$ very dissatisfied, $5=$ very satisfied). Wanous, Reichers, and Hudy (1997) found support for the appropriateness of single-item measures of overall job satisfaction, which correlated highly $(0.67)$ with scale measures.

Intention to Leave. This was measured by three items: "Are you trying to leave the company as soon as possible?"; "Do you enjoy working in your present organisation?" (coding reversed); and "Do you have the feeling that even the slightest change for the worse in your work situation would make

(C) International Association for Applied Psychology, 2001. 
you quit?", and rated on a five-point scale (range: $1=$ definitely not, $5=$ definitely yes). The first two items were adapted and translated into Dutch from the "propensity to leave" scale (Mowday, Steers, \& Porter, 1979). The third item was self-constructed.

Psychological Well-being. This was measured by a short version (six items) of the General Health Questionnaire (GHQ; Banks, 1983; Goldberg, 1978). This questionnaire measures a variety of psychological complaints. Participants were asked how they felt over the past few weeks. Sample items were "Have you recently been able to concentrate on whatever you're doing?", "Have you recently been able to face up to your problems?", and "Have you recently been able to enjoy your normal day-to-day activities?", and were rated on a four-point scale (range: $1=$ much less than usual, $4=$ more than usual). Internal consistencies of study variables (expressed in Cronbach's $\alpha$ ) are reported in Table 1. The internal consistencies of the dependent variables are satisfactory (all $\alpha$ 's are above 0.75). Coefficient $\alpha$ 's for the independent variables are all but one above 0.60 (average $\alpha=0.67$ ), which is regarded as sufficiently reliable given the relatively small number of items on most scales (Briggs \& Cheek, 1986).

\section{Analysis}

According to the procedure proposed by Edwards (1991, 1994), the model for $\mathrm{S}-\mathrm{V}$ fit was tested with moderated regression analysis, using five predictors: work values $(V)$, organisational supplies $(S)$, their quadratic terms $\left(V^{2}\right.$ and $\left.S^{2}\right)$ and the interaction term $\left(S^{*} V\right)$. This procedure permits an examination of complex relationships between variables.

Prior to analysis, organisational supplies and work values measures were scale-centred by subtracting 3 (i.e. the midpoint of each scale), thereby reducing the effects of multicollinearity and allowing meaningful interpretation of coefficients on first-order terms (see Edwards, 1994).

Finally, three-dimensional plots of the estimated surfaces relating supplies, values, and work outcomes were generated and analysed. To interpret the results for each surface, formulas provided by Edwards and Parry (1993) were used. By these formulas the coordinates of the stationary point (i.e. the point at which the slope of the surface is 0 in all directions), the principal axes, and the slopes along the $Y=X$ line, the $Y=-X$ line, and principal axes of the surfaces are calculated. The slopes along the $Y=X$ line and the $Y=-X$ line were tested using standard procedures for linear combinations of regression coefficients. For testing the slopes along the principal axes and the locations of the stationary points and principal axes, a bootstrap procedure was performed as Edwards and Parry (1993) suggested.

(C) International Association for Applied Psychology, 2001. 
TABLE 1

Means, Standard Deviations, Reliability Estimates,

\begin{tabular}{|c|c|c|c|c|c|c|c|c|c|}
\hline Variable & $M$ & $S D$ & 1 & 2 & 3 & 4 & 5 & 6 & 7 \\
\hline \multicolumn{10}{|l|}{ Values at T1 } \\
\hline 1. Extrinsic work aspects & 1.04 & .48 & $(.65)$ & & & & & & \\
\hline 2. Intrinsic work aspects & 1.04 & .45 & $.37 * *$ & $(.64)$ & & & & & \\
\hline 3. Social relations at work & 1.45 & .48 & $.43^{* *}$ & $.29 * *$ & $(.58)$ & & & & \\
\hline \multicolumn{10}{|l|}{ Supplies at $\mathrm{T} 1$} \\
\hline 4. Extrinsic work aspects & .35 & .61 & $.20 * *$ & $.19 * *$ & $.13^{* *}$ & $(.63)$ & & & \\
\hline 5. Intrinsic work aspects & .80 & .69 & .06 & $.23 * *$ & .04 & $.57 * *$ & $(.77)$ & & \\
\hline 6. Social relations at work & 1.09 & .71 & $.15^{* *}$ & $.09 *$ & $.27 * *$ & $.43 * *$ & $.38 * *$ & $(.66)$ & \\
\hline \multicolumn{10}{|l|}{ Values at $\mathrm{T} 2$} \\
\hline 7. Extrinsic work aspects & 1.00 & .48 & $.54 * *$ & $.24 * *$ & $.28 * *$ & .07 & .01 & .08 & $(.66)$ \\
\hline 8. Intrinsic work aspects & 1.10 & .46 & $.20 * *$ & $.48 * *$ & $.13^{* *}$ & $.11 *$ & $.14^{* *}$ & $.09^{*}$ & $.45 * *$ \\
\hline 9. Social relations at work & 1.39 & .51 & $.22 * *$ & $.14 * *$ & $.33^{* *}$ & .00 & .00 & $.11^{* *}$ & $.50 * *$ \\
\hline \multicolumn{10}{|l|}{ Supplies at $\mathrm{T} 2$} \\
\hline 10. Extrinsic work aspects & .37 & .55 & $.15^{* *}$ & $.19 * *$ & $.09^{*}$ & $.31 * *$ & $.19^{* *}$ & $.14^{* *}$ & $.17 * *$ \\
\hline 11. Intrinsic work aspects & .86 & .60 & .03 & $.23^{* *}$ & .04 & $.27 * *$ & $.46^{* *}$ & $.22 * *$ & .01 \\
\hline 12. Social relations at work & 1.06 & .66 & $.09 *$ & $.10 *$ & $.13^{* *}$ & $.17 * *$ & $.21^{* *}$ & $.34 * *$ & $.16^{* *}$ \\
\hline \multicolumn{10}{|l|}{ Work outcomes at $\mathrm{T} 1$} \\
\hline 13. Job satisfaction & 4.30 & .83 & .04 & .01 & .06 & $.52 * *$ & $.48^{* *}$ & $.50 * *$ & .01 \\
\hline 14. Intention to leave & 1.72 & .86 & -.02 & .01 & -.04 & $-.49 * *$ & $-.39^{* *}$ & $-.53^{* *}$ & .01 \\
\hline 15. Psychological well-being & 3.19 & .46 & -.01 & .02 & .00 & $.18^{* *}$ & $.14 * *$ & $.14^{* *}$ & -.00 \\
\hline \multicolumn{10}{|l|}{ Work outcomes at $\mathrm{T} 2$} \\
\hline 16. Job satisfaction & 4.31 & .81 & .02 & .06 & -.01 & .08 & $.11^{*}$ & $.11^{*}$ & .04 \\
\hline 17. Intention to leave & 1.75 & .87 & -.02 & -.03 & .01 & $-.10 *$ & $-.14^{* *}$ & $-.19^{* *}$ & .04 \\
\hline 18. Psychological well-being & 3.19 & .46 & $-.06^{*}$ & -.00 & $-.11 * *$ & .00 & -.00 & .00 & -.04 \\
\hline
\end{tabular}

$N$ ranged from 359 to 456 . Values in parentheses are reliability estimates (coefficient alpha). $* p<0.05$;

\section{RESULTS}

The means, standard deviations, and correlations among the variables used in this study are reported in Table 1.

For all work value measures on both occasions, the means were above the midpoint of the five-point rating scale, indicating that extrinsic rewards, intrinsic rewards, and social relations at work are valued as rather important. (The averages presented in Table 1 reflect the sum of the item scores divided by the number of items in each scale.) The means of all organisational supplies measures were also above the neutral point of the response scale, expressing that the employees rated the extrinsic and intrinsic rewards as well as social relations provided by the organisation as more than sufficient, on average. Furthermore, there was significant consistency between the measures of the independent variables across the two successive occasions (for all correlations, $p<0.01$ ). Stabilities over the four-year period varied

(C) International Association for Applied Psychology, 2001. 
and Intercorrelations of the Study Variables

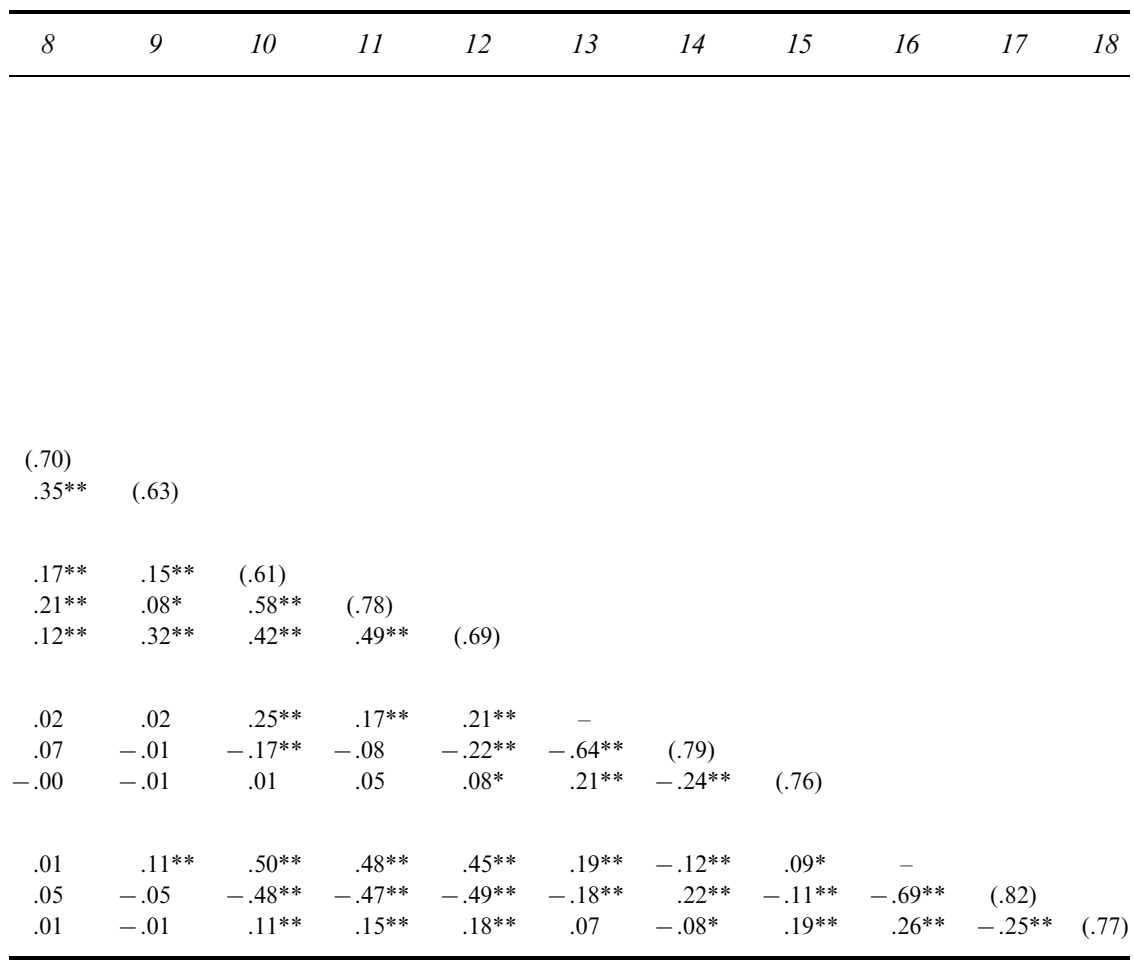

$* * p<0.01$.

between 0.33 and 0.54 for the work values, and were slightly lower but still significant for the organisational supplies (between 0.31 and 0.46). Another interesting finding to be noted in Table 1 is the fairly high negative correlation between job satisfaction and intention to leave $(-0.64$ at $\mathrm{T} 1$ and -0.69 at T2). The correlations between psychological well-being and the other two work outcome variables in the study were significant, but low.

\section{Moderated Regression Analyses}

In this section, the results of all moderated regression analyses are presented. For each of the three dependent variables (job satisfaction, intention to leave, and psychological well-being) only the data regarding Hypotheses 1 and 2 are discussed in this paragraph. Because the data with regard to Hypotheses 3 and 4 are complicated and required additional analyses, they are summarised and discussed in a separate section, "Surface Analyses".

(C) International Association for Applied Psychology, 2001. 
Job Satisfaction. Table 2 shows the results of the moderated regression analyses with job satisfaction as the dependent variable. We first hypothesised that organisational supplies would mainly predict job satisfaction. On both occasions and for all three work aspects, main effects, as a block, accounted for significant variance in job satisfaction (ranging from 19 to $27 \%$; see Table 2, third column). The regression coefficients of all organisational supplies variables were positive and contributed significantly to the prediction of job satisfaction indicating that good social relations at work as well as intrinsic and extrinsic rewards offered by the organisation are positively related to job satisfaction. Regression coefficients of the work values were all lower than those of the organisational supplies, but some of them were significantly related to job satisfaction. Moreover, the regression coefficients of the work values were negative in sign. That is, employees who attached a high value to a particular job characteristic were on average less satisfied with their jobs. Regression coefficients of intrinsic work values contributed significantly to the prediction of job satisfaction on both occasions, but the coefficients of the other two categories of work values only contributed significantly to the prediction of job satisfaction on the first occasion. In sum, it can be concluded that, as predicted by Hypothesis 1 , organisational supplies of all work aspects accounted for most of the variance in job satisfaction on both occasions.

Second, we predicted stronger relationships between organisational supplies and job satisfaction for participants who regard the organisational supply under consideration as important than for those who do not (Hypothesis 2). Quadratic terms and interaction terms for all variables, entered in step 2 of the analysis, mainly accounted for a significant increment in variance explained in job satisfaction on the first occasion (see Table 2, last column). In particular, the quadratic terms of organisational supplies predicted additional variance in job satisfaction; the contribution of the squared value scores was nonsignificant in all cases. The only interaction term that, in combination with a significant effect of the squared supplies term, accounted for an increment in explained variance was the $S^{*} V$ interaction for intrinsic work aspects at $\mathrm{T} 2$.

To summarise, the full moderated regression equations in Table 2 show that differences in job satisfaction were mainly explained by significant linear and quadratic effects of organisational supplies, while the $S^{*} V$ interaction term only accounted for an additional amount of variance in one case. In other words, Hypothesis 2 received little support as far as job satisfaction as the dependent variable was concerned.

Intention to Leave. The results of the moderated regression analyses with intention to leave as the dependent variable are also presented in Table 2. Main effects of work values and organisational supplies, entered as a block,

(C) International Association for Applied Psychology, 2001. 
predicted a significant and substantial amount of variance in intention to leave (range: $20-30 \%$ ). These amounts of explained variances were of the same order of magnitude as the amounts of variances explained in job satisfaction. We hypothesised that intention to leave would be primarily predicted by organisational supplies. All variables, except work values of extrinsic work aspects at $\mathrm{T} 1$, contributed significantly to the explained variance in intention to leave. On both occasions, the signs of the regression coefficients were, as expected, negative for all organisational supplies. In contrast, the signs of the regression coefficients were positive for all work values. Nevertheless, organisational supplies accounted for most of the variance in intention to leave, as predicted by Hypothesis 1 .

Furthermore, we hypothesised stronger relationships between organisational supplies and intention to leave among persons who regard the organisational supply under consideration as important than for those who do not. Results showed that the quadratic terms and the interaction terms of all variables further predicted additional variance in intention to leave, with only one exception, namely social relations at work at the second occasion. When quadratic terms and interaction terms predicted additional variance in intention to leave, the quadratic terms of organisational supplies accounted for most additional variance, sometimes together with the interaction term. However, the contribution of all quadratic terms of work values in the regression equations was small and nonsignificant, and therefore negligible.

To summarise, the regression equations show that main effects of work values and organisational supplies predicted a large amount of variance in intention to leave. Moreover, consistent with Hypothesis 2, the inclusion of the interaction term contributed significantly to the prediction of intention to leave in four out of six analyses.

Psychological Well-being. The results of the regression analyses for psychological well-being, reported in Table 2, show that main effects of work values and organisational supplies entered as a block in the regression equation did not account for as much variance in psychological well-being (variance explained ranged from 3 to $5 \%$ ) as they did in the case of job satisfaction and intention to leave. However, main effects entered as a block in the regression equations still significantly predicted variance in psychological well-being.

We first hypothesised that psychological well-being would be mainly predicted by organisational supplies. The regression coefficients of organisational supplies contributed uniquely to the prediction of psychological well-being in almost all cases, which confirms Hypothesis 1. The only exception was social relations at work at $\mathrm{T} 2$. On this occasion the regression coefficients of both main effects contributed significantly to the prediction of psychological well-being.

(C) International Association for Applied Psychology, 2001. 
TABLE 2

Results of Regression Analyses for S-V Fit with Job Satisfaction, Intention to Leave, and Psychological Well-being as Dependent Variables at $\mathrm{T} 1$ and $\mathrm{T} 2^{\mathrm{a}}$

.

\begin{tabular}{llll}
\hline & \multicolumn{3}{c}{$\begin{array}{c}\text { Unconstrained equation for } \\
\text { monotonic model }\end{array}$} \\
\cline { 2 - 4 } Variables & \multicolumn{2}{c}{$S$} & \multicolumn{2}{c}{$R^{2}$}
\end{tabular}

Unconstrained equation for asymptotic and optimal model
\[ \begin{array}{lllllll}V^{2} & V^{2} & S^{*} V & S^{2} & R^{2} & \Delta R^{2}\end{array} \]

Job satisfaction

Extrinsic work aspects

T1
T2

Intrinsic work aspects

$$
\mathrm{T} 1
$$

$\mathrm{T} 2$

Social relations at work

$$
\text { T1 }
$$

$$
\text { T2 }
$$

$$
\text { T2 }
$$

Intention to leave

Extrinsic work aspects

T1

T2

Intrinsic work aspects

T1

$\mathrm{T} 2$

Social relations at work

T1

$\begin{array}{lrrr}-.211^{*} & .777^{* *} & .271^{* *} & -.412 \\ -.085 & .666^{* *} & .189^{* *} & .285 \\ & & & \\ -.278^{* *} & .750^{* *} & .266^{* *} & -.558^{*} \\ -.171^{*} & .728^{* *} & .234^{* *} & -.462^{*} \\ & & & \\ -.240^{* *} & .631^{* *} & .267^{* *} & -.532 \\ -.124 & .545^{* *} & .190^{* *} & .039\end{array}$

$.709 * *$

$.709 * *$

.098

$-.194$

$.908 * *$

$.519 * *$

.118

$.561^{* *}$

$.598 * *$

.050
-.111

$S^{*} V$

.189

.019

$-.267 * *$

$.297^{*}$
-.087

$.026^{*}$

009

113

$-.228 * * \quad .289^{* *}$

$.023^{*}$

$.488^{* *}-.232 * * \quad .266^{* *} \quad .032 * *$

.212

$-.152 *$

$.286 * *$

$.019^{*}$

\begin{tabular}{|c|c|c|c|c|c|c|c|c|c|}
\hline .169 & $-.816^{* *}$ & $.287 * *$ & -.131 & $-.701 * *$ & .150 & -.258 & $.332 * *$ & $.329 * *$ & $.042 * *$ \\
\hline $.255 * *$ & $-.770 * *$ & $.225 * *$ & .000 & $-.602 * *$ & .191 & $-.365^{*}$ & $.311 * *$ & $.257 * *$ & $.032 * *$ \\
\hline $.194^{*}$ & $-.664 * *$ & $.200 * *$ & .484 & $-.578 * *$ & -.033 & $-.337^{*}$ & $.232 * *$ & $.232 * *$ & $.032 * *$ \\
\hline $.289 * *$ & $-.790 * *$ & $.237 * *$ & $.588 *$ & $-.703 * *$ & .021 & $-.406^{* *}$ & $.255^{* *}$ & $.261 * *$ & $.024 * *$ \\
\hline $.225 *$ & $-.673 * *$ & $.296 * *$ & .337 & $-.656^{* *}$ & .023 & -.220 & $.197 * *$ & $.322 * *$ & $.026^{* *}$ \\
\hline $.233^{* *}$ & $-.670 * *$ & $.240 * *$ & .305 & $-.479^{*}$ & .065 & $-.240^{*}$ & .079 & $.248^{* *}$ & .008 \\
\hline
\end{tabular}

.009 
TABLE 2 (contd)

\begin{tabular}{|c|c|c|c|c|c|c|c|c|c|c|}
\hline \multirow[b]{2}{*}{ Variables } & \multicolumn{3}{|c|}{$\begin{array}{l}\text { Unconstrained equation for } \\
\text { monotonic model }\end{array}$} & \multicolumn{7}{|c|}{ Unconstrained equation for asymptotic and optimal model } \\
\hline & $V$ & $S$ & $R^{2}$ & $V$ & $S$ & $V^{2}$ & $S^{*} V$ & $S^{2}$ & $R^{2}$ & $\Delta R^{2}$ \\
\hline \multicolumn{11}{|c|}{ Psychological well-being } \\
\hline \multicolumn{11}{|c|}{ Extrinsic work aspects } \\
\hline $\mathrm{T} 1$ & -.068 & $.184 * *$ & $.050 * *$ & -.148 & .002 & .018 & $.211^{*}$ & $-.114^{*}$ & $.075^{* *}$ & $.025 *$ \\
\hline $\mathrm{T} 2$ & -.034 & $.152 * *$ & $.027 * *$ & -.235 & .118 & .110 & -.051 & $.121 *$ & $.044 * *$ & .017 \\
\hline \multicolumn{11}{|c|}{ Intrinsic work aspects } \\
\hline $\mathrm{T} 1$ & .044 & $.141 * *$ & $.038 * *$ & -.083 & .001 & .000 & .163 & -.032 & $.049 * *$ & .011 \\
\hline $\mathrm{T} 2$ & -.052 & $.160 * *$ & $.031 * *$ & -.061 & .008 & -.053 & .122 & .013 & $.037 * *$ & .006 \\
\hline \multicolumn{11}{|c|}{ Social relations at work } \\
\hline $\mathrm{T} 1$ & -.091 & $.113^{* *}$ & $.030^{*}$ & -.325 & .094 & .069 & .079 & -.060 & $.042 *$ & .012 \\
\hline $\mathrm{T} 2$ & $-.111^{*}$ & $.176^{* *}$ & $.053 * *$ & -.131 & .136 & -.038 & .120 & -.071 & $.063 * *$ & .010 \\
\hline
\end{tabular}

${ }^{\text {a }} N$ ranged from 359 to 456 . For all columns except those labelled $R^{2}$, table entries are unstandardised regression coefficients for equations with all predictors entered simultaneously. $\mathrm{V}=$ Work values, $\mathrm{S}=$ Organisational supplies. ${ }^{*} p<0.05$ and $* * p<0.01$. 
Second, we predicted stronger relationships between organisational supplies and psychological well-being among employees who regard the organisational supply under consideration as important than among those who do not. The quadratic terms of work values and organisational supplies regarding extrinsic work aspects at $\mathrm{T} 1$ and their interaction term was the only block of variables that significantly contributed to explained variance in psychological well-being. At both occasions, just for one of the three work aspects a significant $S^{*} V$ interaction was found in these analyses. Significant regression coefficients were obtained for the quadratic term of organisational supplies and the interaction between organisational supplies and work values. In other words, Hypothesis 2 regarding psychological wellbeing was not supported.

\section{Surface Analyses}

Finally, we hypothesised that the form of the relationship between S-V fit and work outcomes would depend upon the specific work aspect and work outcome involved. Regarding intrinsic work aspects and social relations at work, Hypothesis 3 predicted U-shaped or inverted U-shaped relationships with the dependent variables, while for extrinsic work aspects satiation effects were expected (Hypothesis 4). For a thorough interpretation of the significant data presented in Table 2, a number of three-dimensional graphs were plotted, and corresponding surface analyses were performed (see Edwards \& Parry, 1993). In these analyses the following parameters were calculated and tested: the stationary point, the principal axes, and the slopes along the lines of interest. The results of these surface analyses are reported in Table 3 and Table 4. In the remainder of this section, the results are successively discussed for the three dependent variables.

Job Satisfaction. Because the interaction term of intrinsic work aspects at $\mathrm{T} 2$ was the only interaction term that accounted for an increment in explained variance in job satisfaction, it was not meaningful to compare the surfaces for the three different work aspects. Both Hypotheses 3 and 4 received little support from our data. The predicted effects were found only for intrinsic work values and organisational supplies at the second occasion. The surface depicting the moderated regression equation for intrinsic work values and supplies at T2 is presented in Fig. 1.

Regarding the relationship between intrinsic S-V fit and job satisfaction, we hypothesised that job satisfaction would be low when intrinsic work values exceed organisational supplies and that job satisfaction would be maximised at the point of perfect fit (i.e. $S$ equals $V$ ). Furthermore, we hypothesised that job satisfaction would decrease again when organisational supplies exceed intrinsic work values. This implies a ridge with its

(C) International Association for Applied Psychology, 2001. 
TABLE 3

Stationary Points and Principal Axes ${ }^{\mathrm{a}}$

\begin{tabular}{|c|c|c|c|c|c|c|c|}
\hline \multirow[b]{2}{*}{ Work aspect } & \multirow[b]{2}{*}{ Work outcome } & \multicolumn{2}{|c|}{ Stationary point } & \multicolumn{2}{|c|}{ First principal axis } & \multicolumn{2}{|c|}{ Second principal axis } \\
\hline & & $X_{O}$ & $Y_{O}$ & $P_{10}$ & $P_{11}$ & $P_{20}$ & $P_{21}$ \\
\hline & At $\mathrm{T} 1$ & & & & & & \\
\hline Intrinsic work aspects & Intention to leave & 0.207 & $1.396^{*}$ & 1.821 & -2.058 & $1.295^{*}$ & $0.486^{\mathrm{c}}$ \\
\hline Social relations at work & Intention to leave & -0.381 & 1.452 & 0.665 & -2.066 & 1.637 & 0.484 \\
\hline Extrinsic work aspects & Intention to leave & 2.019 & $1.840^{*}$ & 5.736 & -1.929 & 0.794 & 0.518 \\
\hline Intrinsic work aspects & Intention to leave & 0.101 & $1.459 * *$ & 1.633 & $-1.731^{*}$ & $1.400 * *$ & $0.578^{* * \mathrm{~b}, \mathrm{c}}$ \\
\hline Social relations at work & Intention to leave & -1.802 & 0.295 & -1.615 & -1.060 & $1.995^{*}$ & $0.943^{*}$ \\
\hline Extrinsic work aspects & Intention to leave & 2.105 & 2.203 & 5.111 & -1.381 & 0.679 & $0.724^{*}$ \\
\hline Intrinsic work aspects & Job satisfaction & -0.218 & 0.890 & $1.045^{*}$ & 0.713 & 0.585 & $-1.402^{* *}$ \\
\hline
\end{tabular}

${ }^{a} N$ ranged from 359 to 456 . For columns labelled $X_{0}$ and $Y_{0}$, table entries are the coordinates of the stationary point in the $X, Y$ plane. For columns labelled $\mathrm{p}_{10}$ and $\mathrm{p}_{11}$, table entries are the intercept and slope of the first principal axis in the $X, Y$ plane; and for the columns labelled $\mathrm{p}_{20}$ and $\mathrm{p}_{21}$, table entries are the intercept and slope of the second principal axis in the $X, Y$ plane. Standard errors for all values were estimated using a bootstrap procedure.

${ }^{\mathrm{b}}$ For this surface, the slope and the second principal axis $\left(\mathrm{p}_{21}\right)$ differed significantly from $1(p<0.05)$.

${ }^{\mathrm{c}}$ For this surface, the quantity $-\mathrm{p}_{20} /\left(1+\mathrm{p}_{21}\right)$ was significantly less than $0(p<0.05)$, indicating a lateral shift of the second principal axis along the $Y=-X$ line into the region where $X$ is less than $Y$.

$* p<0.05$ and $* * p<0.01$. 
TABLE 4

Slopes Along Lines of Interest

\begin{tabular}{|c|c|c|c|c|c|c|c|c|c|}
\hline \multirow[b]{2}{*}{ Work aspect } & \multirow[b]{2}{*}{ Work outcome } & \multicolumn{2}{|c|}{$Y=X$} & \multicolumn{2}{|c|}{$Y=-X$} & \multicolumn{2}{|c|}{ First principal axis } & \multicolumn{2}{|c|}{$\begin{array}{l}\text { Second principal } \\
\text { axis }\end{array}$} \\
\hline & & $a_{x}$ & $a_{x}^{2}$ & $a_{x}$ & $a_{x}^{2}$ & $a_{x}$ & $a_{x}^{2}$ & $a_{x}$ & $a_{x}^{2}$ \\
\hline & At Time 1 & & & & & & & & \\
\hline Intrinsic work aspects & Intention to leave & -0.094 & -0.138 & $1.062 * *$ & $0.536^{*}$ & -0.679 & 1.644 & 0.059 & -0.142 \\
\hline Social relations at work & Intention to leave & -0.319 & 0.000 & $0.993^{*}$ & $0.440^{*}$ & 1.005 & 1.318 & -0.028 & -0.037 \\
\hline Extrinsic work aspects & Intention to leave & $-0.832^{*}$ & 0.224 & 0.570 & $0.740 * *$ & -7.606 & 1.883 & -0.426 & 0.105 \\
\hline & At Time 2 & & & & & & & & \\
\hline Intrinsic work aspects & Intention to leave & -0.115 & -0.130 & $1.291 * *$ & $0.682 * *$ & -0.300 & $1.487^{*}$ & 0.026 & -0.128 \\
\hline Social relations at work & Intention to leave & -0.174 & -0.096 & $0.784 * *$ & $0.384^{*}$ & 1.471 & 0.408 & -0.328 & -0.091 \\
\hline Extrinsic work aspects & Intention to leave & $-0.602 *$ & 0.137 & $0.602 *$ & $0.867^{* *}$ & -5.426 & 1.289 & -0.378 & 0.090 \\
\hline Intrinsic work aspects & Job satisfaction & 0.057 & 0.192 & $-0.981 * *$ & $-0.784 * *$ & 0.072 & 0.166 & -0.524 & -1.204 \\
\hline
\end{tabular}

${ }^{a} N$ ranged from 359 to 456 . For each line $\mathrm{a}_{\mathrm{x}}$ represents the computed coefficient on $X$, and $\mathrm{a}_{\mathrm{x}}^{2}$ represents the computed coefficient on $X^{2}$. Standard errors for slopes along the $Y=X$ and $Y=-X$ lines were derived using standard rules for the variance of linear combination of random variables and standard errors for the slopes along the principal axes were estimated using a bootstrap procedure.

$* p<0.05$ and $* * p<0.01$. 


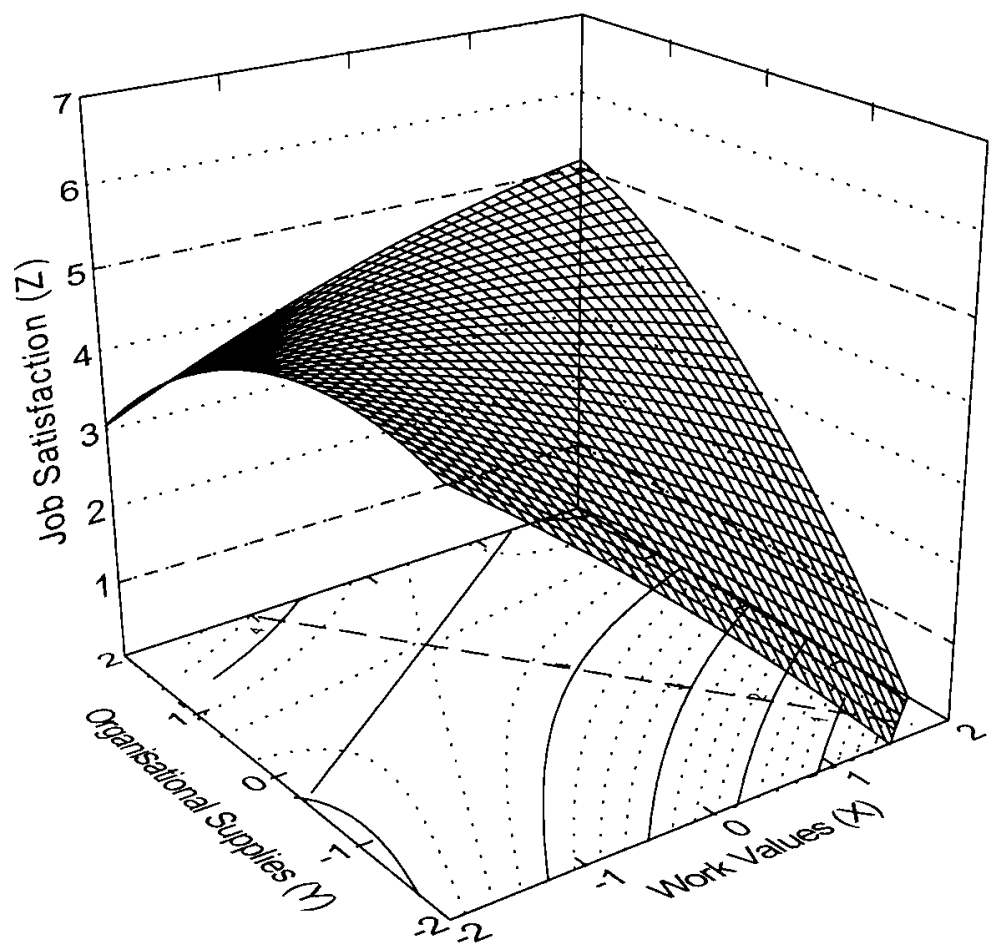

FIGURE 1. Estimated surface for the relationship of S-V fit (intrinsic work aspects) with job satisfaction at $\mathrm{T}^{\mathrm{a}}$

${ }^{a}$ When the principal axes cross the $X, Y$ plane within the range of the $X$ and $Y$ measures, the first principal axis is represented by a solid line and the second principal axis is represented by a dashed line.

first principal axis running along the $X=Y$ line, meaning that $p_{11}=1$ and $-p_{10} /\left(1+p_{11}\right)=0$. Results showed that the slope of the first principal axis was slightly but not significantly smaller than $1\left(p_{11}=0.713\right)$. In addition, the quantity of $-p_{10} /\left(1+p_{11}\right)$ was negative, but did not differ significantly from $0(-0.610, p>0.05)$. These findings, combined with the location of stationary point $\left(X_{0}=-0.218, Y_{0}=0.890\right)$, indicate a small lateral shift along the $Y=-X$ line into the region where intrinsic work values are less than organisational supplies and a small clockwise rotation of the surface of the $Y=X$ line. Furthermore, the surface along the $Y=X$ was almost flat ( $a_{x}=0.057$ and $a_{x}{ }^{2}=0.192$, both n.s.), whereas the slope along the $Y=-X$ line was concave $\left(a_{x}^{2}=-0.784, p>0.01\right)$ and negative at the origin $\left(a_{x}=-0.981, p>0.01\right)$. Overall, the surface indicates that job satisfaction decreases when intrinsic work values deviate from organisational supplies, as predicted by Hypothesis 3. As was mentioned earlier in this section, no

(C) International Association for Applied Psychology, 2001. 
significant interaction effects were found regarding extrinsic work aspects and social relations at work. Therefore, further surface analyses would be superfluous. In sum, the effects predicted by Hypothesis 3 were found in just one case.

a) Intrinsic work aspects

at $\mathrm{T} 1$

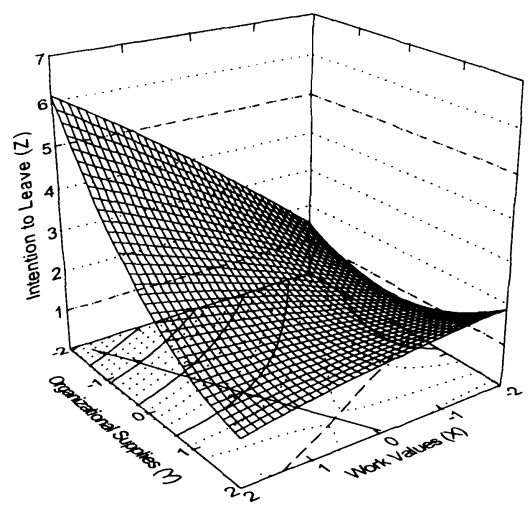

at $\mathrm{T} 2$

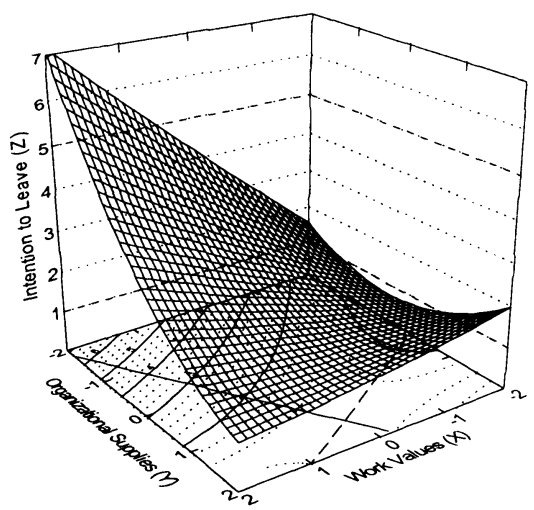

b) Social relations at work

at $\mathrm{T} 1$

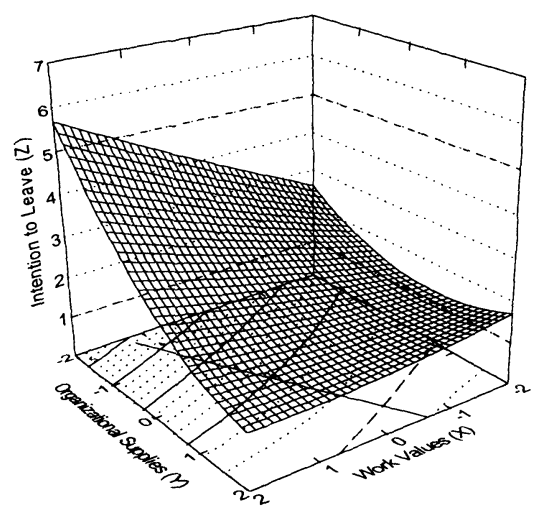

at $\mathrm{T} 2$

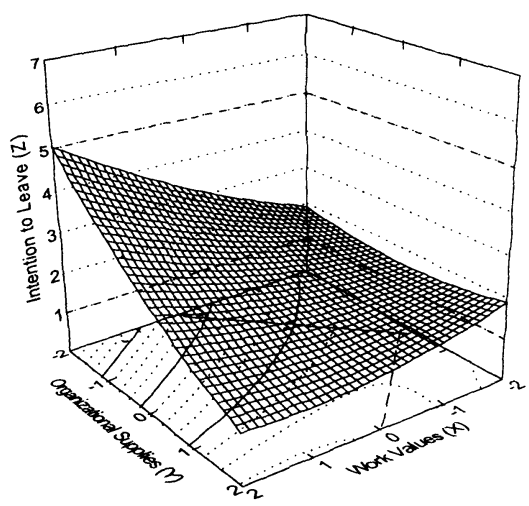

FIGURE 2. Estimated surfaces for three relationships of $S-V$ fit with intention to leave at two occasions (T1 and T2) ${ }^{\mathrm{a}}$

${ }^{a}$ When the principal axes cross the $X, Y$ plane within the range of the $X$ and $Y$ measures, the first principal axis is represented by a solid line and the second principal axis is represented by a dashed line.

(C) International Association for Applied Psychology, 2001. 
c) Extrinsic work aspects

at $\mathrm{T} 1$

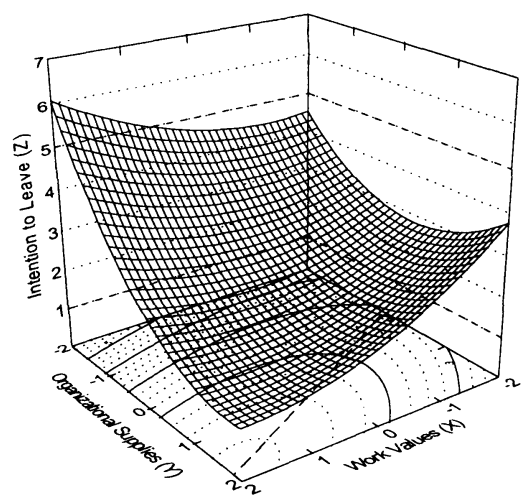

at $\mathrm{T} 2$

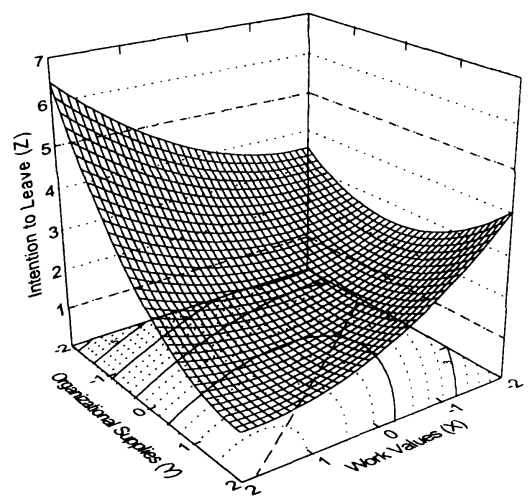

FIGURE 2 (contd)

Intention to Leave. We proposed that the shape of the surface representing the relationship between extrinsic work aspects and intention to leave would deviate from the surfaces depicting the relationship of intention to leave with intrinsic work aspects or with social relations at work. Fig. 2 presents graphs of estimated surfaces relating $\mathrm{S}-\mathrm{V}$ fit to intention to leave. We hypothesised that for intrinsic work aspects and social relations at work, intention to leave would be high when work values deviate from organisational supplies (Hypothesis 3). This hypothesis implies a trough with its second principal axis running along the $Y=X$ line, meaning that $p_{20}=0$ and $p_{21}=1$. If $p_{21}$ differs from 1 , the surface is rotated off the $Y=X$ line, whereas if the quantity of $-p_{20} /\left(1+p_{21}\right)$ differs from 0 , the surface is shifted laterally along the $Y=-X$ line. Either result would indicate that the second principal axis deviates from the $Y=X$ line.

The surfaces at T1 and T2 for intrinsic work values and organisational supplies predicting intention to leave were saddle-shaped (see Figure 2). The second principal axes were at both occasions rotated clockwise of the $Y=X$ line, but this rotation was only significant at T2 $\left(p_{21}=0.578, p<0.01\right)$. At both occasions, the second principal axis showed a significant lateral shift along the $Y=-X$ line into the region where $X$ is less than $Y\left(-p_{20} /\left(1+p_{21}\right)\right.$ $=-0.871$ at $\mathrm{T} 1$ and $-p_{20} /\left(1+p_{21}\right)=-0.887$ at $\mathrm{T} 2$, both $p<0.05$. The slope of both surfaces for intrinsic work values were curved upwards along the $Y=-X$ line $\left(a_{x}{ }^{2}=0.536, p<0.05\right.$ at T1; $a_{x}{ }^{2}=0.682, p<0.01$ at T2) and flat at the point where $Y=X\left(a_{x}=-0.094\right.$ and $a_{x}{ }^{2}=-0.138$ at T1, and $a_{x}=-0.115$ and $a_{x}{ }^{2}=-0.130$ at $\mathrm{T} 2$; for all $\left.p>0.05\right)$. These results, presented in Fig. 2 and Tables 3 and 4, indicated that intention to leave is

(C) International Association for Applied Psychology, 2001. 
minimised when intrinsic work values are slightly less than organisational supplies. However, when intrinsic work values are much less than organisational supplies, intention to leave increased again.

The surfaces at $\mathrm{T} 1$ and $\mathrm{T} 2$ for social relations at work predicting intention to leave were also saddle-shaped (see Fig. 2). At both occasions the slope of the second principal axis did not differ from 1, indicating no appreciable rotation of the $Y=X$ line. Besides, the value of $-p_{20} /\left(1+p_{21}\right)$ of both surfaces did not differ from $0\left(-p_{20} /\left(1+p_{21}\right)=-1.103\right.$ at $\mathrm{T} 1$ and $-p_{20} /$ $\left(1+p_{21}\right)=-1.027$ at $\mathrm{T} 2$, both $\left.p>0.05\right)$, indicating no lateral shifts of the second principal axes off the $Y=X$ line. Both surfaces were flat along the $Y=X$ line $\left(a_{x}=-0.319\right.$ and $a_{x}{ }^{2}=-0.000$ at $\mathrm{T} 1$, and $a_{x}=-0.174$ and $a_{x}{ }^{2}=-0.096$ at T2; for all $p=$ n.s.), and moderately convex along the $Y=-X$ line, with positive slopes where they crossed the $Y$-axes $\left(a_{x}=0.993\right.$ and $a_{x}{ }^{2}=0.440$ at T1, both $p<0.05 ; a_{x}=0.784, p<0.01$ and $a_{x}{ }^{2}=0.384$, $p<0.05$ at T2). Overall, these results indicated that intention to leave increased as work values regarding social relations at work deviated from the organisational supplies. Moreover, intention to leave increased more when work values exceeded organisational supplies than when organisational supplies exceeded work values.

As appears from Fig. 2, the surfaces at T1 and T2 for extrinsic work values and organisational supplies predicting intention to leave were both convex, with their stationary point at $X=2.019$ and $Y=1.840$ at $\mathrm{T} 1$, and $X=2.105$ and $Y=2.203$ at T2, both just outside the near corner of their $X, Y$ planes. The slopes of their second principal axes were 0.518 and 0.724 respectively, representing slight but nonsignificant rotations from the $Y=X$ line. The slopes along the $Y=-X$ lines were convex at both occasions $\left(a_{x}^{2}=0.740\right.$ at T1, $p<0.01$, and $a_{x}{ }^{2}=0.867, p<0.01$ at T2) and only at the second occasion slightly positive at the origin $\left(a_{x}=0.602, p<0.05\right)$. These results indicated that at both occasions intention to leave increased as extrinsic work values differs more from organisational supplies. Further analyses showed that the slope of both surfaces along the $Y=X$ line were negative and linear, thereby indicating that intention to leave was lower when both extrinsic work values and organisational supplies were both high than when both were low.

As hypothesised, intention to leave decreased for all work aspects when more of these aspects were offered by the organisation. With respect to extrinsic work aspects, however, results showed effects opposite of what was expected. When more extrinsic work aspects were offered than valued as important, intention to leave increased, while for intrinsic work values and social relations at work the intention to leave did not change. Although all these effects were not predicted, they were very stable across both occasions.

Psychological Well-being. Regression analyses revealed that predominantly main effects of organisational supplies significantly predicted

(C) International Association for Applied Psychology, 2001. 
psychological well-being. These effects were equally strong for extrinsic work aspects, intrinsic work aspects and social relations at work across both occasions. Graphs of the relationships between organisational supplies, work values, and psychological well-being would not further facilitate interpretation of these results and are therefore not displayed.

\section{DISCUSSION}

This study examined the functional form of the relationship between work values, organisational supplies, and work outcomes on two successive occasions. With regard to three different work aspects - intrinsic work aspects, extrinsic work aspects, and social relations at work-linear and curvilinear effects as well as interaction effects of work values and organisational supplies on job satisfaction, intention to leave, and psychological well-being were studied.

As predicted by Hypothesis 1, organisational supplies accounted for more variance in work outcomes than did work values. Larger amounts of variance were explained by individual differences in experienced organisational supplies than by individual differences in work values. This was consistently found for all three work aspects, for all three work outcomes, and on both occasions of data collection. Further, the signs of all the regression coefficients of organisational supplies were always in the direction predicted by the hypothesis. In other words, when the organisation provided their employees more extrinsic and intrinsic rewards as well as social relationships, they were more satisfied, experienced fewer psychological complaints, and had less intention to leave.

Although not predicted, results showed that main effects of work values also significantly explained some variance in job satisfaction and intention to leave. Moreover, these effects as well as their direction were fairly stable across a four-year period. These results indicated that people were less satisfied and had stronger intentions to leave when work aspects were valued as more important. Probably, people who place more importance on intrinsic and extrinsic work aspects as well as on social relations in their job are at higher risk of getting discontented.

The effects (linear as well as curvilinear) of work values and organisational supplies on psychological well-being were weak. The total amount of explained variance in psychological well-being was significant, but low $\left(R^{2}\right.$, s varied between 0.037 and 0.075$)$ compared to the amount of explained variance in job satisfaction $\left(R^{2}\right.$,s varied between 0.198 and 0.297$)$ or intention to leave $\left(R^{2}\right.$ s varied between 0.232 and 0.329$)$. An explanation of this finding may be that "context-free" (as it is called by Warr, 1987) psychological well-being is determined predominantly by other factors, in or outside the work domain, that are not measured in this study, for example neuroticism or stressful life events.

(C) International Association for Applied Psychology, 2001. 
As predicted by Hypothesis 2, the interaction between organisational supplies and work values was significant in some cases. Most notably, the interaction term explained a significant amount of additional variance in intention to leave in four out of the six analyses. The significant interaction terms were always in the expected direction, indicating that the relationships between organisational supplies and intention to leave were stronger for those employees who valued a particular work aspect as more important.

The significant interactions between organisational supplies and work values in predicting work outcomes were mostly found on the second occasion but not the first. The only significant $S^{*} V$ interaction effect which was replicable across both occasions was the interaction effect of intrinsic values and supplies on intention to leave. Lack of significant $S^{*} V$ interaction terms in predicting work outcomes may be attributed to the fact that data were obtained in real work settings. Schneider (1983), for instance, argued that in most real work settings extreme mismatches between personal and organisational characteristics hardly exist. People select themselves into settings they fit and out of settings they do not fit. In other words, in natural settings there is a restriction of range of $\mathrm{S}-\mathrm{V}$ fit measures. According to Schneider (1983), this restriction of range in S-V fit at best produces linear effects for work values and organisational supplies in the prediction of work behaviour. However, the findings of the present study do not support this explanation. Four out of the six significant interactions were found on the second occasion as participants were four years older and should therefore fit better with their jobs.

An alternative explanation is offered by a study of Kristof-Brown, Bono, and Lauver (1999). They distinguish between two kinds of fit, actual fit and perceived fit, which change in different ways during a working career. Perceived fit, as was measured in our study, probably becomes more accurate over time, since people become more aware of their own characteristics as well as of the characteristics of their working environment. This might be the reason why perceived fit predicted work outcomes at the second occasion better than at the first occasion. These results underscore the importance of focusing in future studies not only on the relationships between work environmental characteristics and work outcomes, but also on the personal characteristics that positively or negatively affect these relationships.

What can we conclude about differences between the three domains of work aspects as far as the functional form of their relationships with work outcomes is concerned? With regard to job satisfaction we can conclude that there were no striking differences between extrinsic and intrinsic work aspects and social relations at work. In all cases job satisfaction was predicted by linear and curvilinear effects of organisational supplies, while work values as well as $S^{*} V$ interactions revealed no consistent effects. Only

(C) International Association for Applied Psychology, 2001. 
for intrinsic work aspects were main effects of values and interactions found. Job satisfaction was higher for those who valued intrinsic work aspects as more important. Moreover, satisfaction became higher with an increasing amount of perceived supplies up to the point of satiation, and then decreased. This result clearly confirms the theories of Locke (1976) and Mahoney (1979) and, more specifically, ideas of Warr (1987) that job satisfaction decreases when intrinsic work values deviate from organisational supplies, providing partial support for Hypothesis 3.

The functions relating intention to leave to extrinsic work aspects, intrinsic work aspects, and social relations at work were roughly equal: they mostly included significant linear as well as quadratic effects of supplies, and in a number of cases significant $S^{*} V$ interactions. However, results failed to support Hypothesis 4; instead they revealed one unexpected finding: intention to leave decreased when extrinsic organisational supplies increased until an employee's valued level was reached but, surprisingly, again increased beyond the employee's valued level. This tendency was replicable across occasions. Thus, excessive amounts of extrinsic supplies, such as salary or job security, apparently stimulate employees to leave the company.

\section{Limitations of this Study and Recommendations for Future Research}

Although this study yields some important findings, it has some limitations. A first limitation of this study is that the internal consistencies of some of the scales were not very high. It appeared that scales that had the highest internal consistencies, that is measuring work values and organisational supplies of intrinsic work aspects, also showed the strongest interaction effects in this study. However, almost without exception internal consistencies of scales increased from the first to the second occasion. This might be caused by the self-report character of the measures. The increase in internal consistencies seems to confirm the idea of Kristof-Brown et al. (1999) that people become more aware of their own characteristics as well as the properties of their work environment during their working careers, and are therefore becoming more accurate in their self-reports. A dilemma for future research lies in deciding at which stage of someone's working career perceived P-E fit should be measured: at the beginning, when self-reports are inaccurate, but reveal a great amount of variance in $\mathrm{P}-\mathrm{E}$ fit, or towards the end of people's careers when the accuracy of fit perceptions increases, but the range of fit measures is restricted?

In the present study, results showed that both work values and supplies regarding intrinsic work aspects increased during one's working career. However, results obtained by Van der Velde and Feij (1995) suggested that these increases are only found for persons who change jobs. Results of their

(C) International Association for Applied Psychology, 2001. 
study showed that an increase in supplies offered by the organisation depends on whether someone changed jobs or stayed in the same job. Persons who changed jobs perceived an increase in intrinsic work aspects on two successive occasions, while persons in the same job perceived a decrease in intrinsic work aspects. In the present study, no distinction was made between persons in the same job and persons who changed jobs, because statistical power would be limited due to the sample size of these two subsamples. However, future research should pay attention to this point.

\section{Concluding Remarks}

Mindful of Kurt Lewin's dictum that there is nothing so practical as a good theory, Locke's value theory (1976) and Warr's vitamin model (1987) were both applied in the present study to address questions regarding the influence of the interaction between organisational supplies and values on job satisfaction, intention to leave, and psychological well-being as well as the contribution of several components to these effects. Response surface methodology as proposed by Edwards $(1991,1994)$ was used to examine the relationship between the $S^{*} V$ interaction and work outcomes on three dimensions.

In summary, the present study demonstrated that organisational supplies and, to a lesser degree, work values are predictors of an employee's job satisfaction and intention to leave. Furthermore, work values moderate the relationship of organisational supplies with intention to leave. These findings were largely replicated on two successive occasions indicating the robustness of these effects. The results largely confirm the hypotheses put forward by Locke's theory and Warr's vitamin model. From a practical point of view, the implication of the findings presented here is that rewards supplied by the organisation result in positive work outcomes, especially when an employee values these rewards as important. However, excessive amounts of these supplies may have a detrimental effect on the employee's job satisfaction, and will enhance the intention to leave the organisation.

\section{REFERENCES}

Assouline, M., \& Meir, E.I. (1987). Meta-analysis of the relationship between congruence and well-being measures. Journal of Vocational Behavior, 31(3), 319-332.

Banks, M.H. (1983). Validation of the general health questionnaire in a young community sample. Psychological Medicine, 13, 349-353.

Briggs, S.R., \& Cheek, J.M. (1986). The role of factor analysis in the development and evaluation of personality scales. Journal of Personality, 54, 106-148.

Chatman, J.A. (1989). Improving interactional organizational research: A model of person-organization fit. Academy of Management Review, 14(3), 333-349.

(C) International Association for Applied Psychology, 2001. 
Chatman, J.A. (1991). Matching people and organizations: Selection and socialization in public accounting firms. Administrative Science Quarterly, 36(3), 459-484.

Cohen, A. (1992). Antecedents of organizational commitment across occupational groups: A meta-analysis. Journal of Organizational Behavior, 13(6), 539-558.

Dawis, R.V., \& Lofquist, L.H. (1984). A psychological theory of work adjustment: An individual-differences model and its applications. Minneapolis, MN: University of Minnesota Press.

Dijkstra, W. (Ed.) (1989). Het proces van sociale integratie van jong-volwassenen: De gegevensverzameling voor de eerste hoofdmeting [The process of social integration of young adults: The first main survey]. Amsterdam: VU-Uitgeverij.

Dijkstra, W. (1993). Het proces van sociale integratie van jong-volwassenen: De tussenmeting en de tweede hoofdmeting [The process of social integration among young adults: The second and third wave]. Amsterdam: Vrije Universiteit.

Edwards, J.R. (1991). Person-job fit: A conceptual integration, literature review, and methodological critique. In C.L. Cooper \& I.T. Robertson (Eds.), International review of industrial and organizational psychology (Vol. 6, pp. 283-357). Chichester: Wiley.

Edwards, J.R. (1994). The study of congruence in organizational behavior research: Critique and a proposed alternative. Organizational Behavior and Human Decision Processes, 58, 51-100.

Edwards, J.R. (1996). An examination of competing versions of the person-environment fit approach to stress. Academy of Management Journal, 39(2), 292-339.

Edwards, J.R., \& Parry, M.E. (1993). On the use of polynomial regression equations as an alternative to difference scores in organizational research. Academy of Management Journal, 36(6), 1577-1613.

French, J.R.P.J., Caplan, R.D., \& Van Harrison, R. (1982). The mechanisms of job stress and strain. Chichester: Wiley.

Ganzach, Y. (1998). Nonlinearity, multicollinearity and the probability of type II error in detecting interaction. Journal of Management, 24(5), 615-622.

Ginzberg, E., Ginsburg, S.W., Axelrad, S., \& Herma, J.L. (1951). Occupational choice: An approach to a general theory. New York: Columbia University Press.

Goldberg, D.P. (1978). Manual for the general health questionnaire. Windsor: National Foundation for Educational Research.

Hesketh, B., \& Gardner, D. (1993). Person-environment fit models: A reconceptualization and empirical test. Journal of Vocational Behavior, 42(3), 315-332.

Holland, J.L. (1992). Making vocational choices: A theory of vocational personalities and work environments, (3rd edn.). Odessa, FL: Psychological Assessment Resources, Inc.

Kristof, A.L. (1996). Person-organization fit: An integrative review of its conceptualizations, measurement, and implications. Personnel Psychology, 49(1), $1-49$.

Kristof-Brown, A., Bono, J.E., \& Lauver, K.J. (1999). Learning to fit in: How socialization affects perceived and actual person-environment fit. Paper presented at the 14th Annual Conference of the Society for Industrial and Organizational Psychology, Atlanta, GA.

Lewin, K. (1951). Field theory in social science: Selected theoretical papers. London: Tavistock.

(C) International Association for Applied Psychology, 2001. 
Livingstone, L.P., Nelson, D.L., \& Barr, S.H. (1997). Person-environment fit and creativity: An examination of supply-value and demand-ability versions of fit. Journal of Management, 23(2), 119-146.

Locke, E.A. (1976). Nature and causes of job satisfaction. In M.D. Dunnette (Ed.), Handbook of industrial and organizational psychology (pp. 1297-1349). Chicago: Rand McNally.

Mahoney, T.A. (1979). Another look at job satisfaction and performance. In T.A. Mahoney (Ed.), Compensation and reward perspectives (pp. 322-334). Homewood, IL: Irwin.

Mathieu, J.E., \& Zajac, D.M. (1990). A review and meta-analysis of the antecedents, correlates, and consequences of organizational commitment. Psychological Bulletin, 108(2), 171-194.

Meyer, J.P., Irving, P.G., \& Allen, N.J. (1998). Examination of the combined effects of work values and early work experiences on organizational commitment. Journal of Organizational Behavior, 19(1), 29-52.

MOW International Research Team (1987). The meaning of working. London: Academic Press.

Mowday, R.T., Steers, R.M., \& Porter, L.W. (1979). The measurement of organizational commitment. Journal of Vocational Behavior, 14, 224-247.

O'Brien, G.E., \& Dowling, P. (1980). The effects of congruency between perceived and desired job attributes upon job satisfaction. Journal of Occupational Psychology, 53(2), 121-130.

Rice, R.W., Markus, K., Moyer, R.P., \& McFarlin, D.B. (1991). Facet importance and job satisfaction: Two experimental tests of Locke's range of affect hypothesis. Journal of Applied Social Psychology, 21(24), 1977-1987.

Rokeach, M. (1973). The nature of human values. New York: The Free Press.

Schneider, B. (1983). Interactional psychology and organizational behavior. Research in Organizational Behavior, 5, 1-31.

Spokane, A.R. (1985). A review of research on person-environment congruence in Holland's theory of careers. Journal of Vocational Behavior, 26(3), 306-343.

Taris, A.W., Van der Vaart, W., \& Dijkstra, W. (1993). Non-respons en representativiteit van de follow-up metingen [Non-response and representivity of the waves]. In W. Dijkstra (Ed.), Het proces van sociale integratie van jongvolwassenen: De tussenmeting en de tweede hoofdmeting [The process of social integration among young adults: The second and third wave] (pp. 65-76). Amsterdam: Vrije Universiteit.

Van der Velde, M.E.G., \& Feij, J.A. (1995). Change of work perceptions and work outcomes as a result of voluntary and involuntary job change. Journal of Occupational \& Organizational Psychology, 68(4), 273-290.

Wanous, J.P., Reichers, A.E., \& Hudy, M.J. (1997). Overall job satisfaction: How good are single-item measures? Journal of Applied Psychology, 82(2), 247-252.

Warr, P. (1987). Work, unemployment, and mental health. Oxford: Clarendon Press.

WOSY International Research Group (1989). Interview schedule of the work socialization of youth study. Gent: Laboratory for Sociopsychology of Work and Organization and for Test Construction.

(C) International Association for Applied Psychology, 2001. 